\title{
Inhibition impact of 1-phenyl-2-pyrazolin-5-one derivatives on corrosion of 304 stainless steel in molar $\mathrm{HCl}$ solution
}

\author{
A.S. Fouda, ${ }^{1}\left[\right.$ * S.M. Rashwan, ${ }^{2}$ M.M. Kamel, ${ }^{2}(\mathbb{0}$ \\ A.H.M. Gad ${ }^{2}$ and K. Shalabi ${ }^{1}$ \\ ${ }^{1}$ Department of Chemistry, Faculty of Science, Mansoura University, Mansoura 35516, \\ Egypt \\ ${ }^{2}$ Department of Chemistry, Faculty of Science, Suez Canal University, Egypt \\ *E-mail: asfouda@hotmail.com
}

\begin{abstract}
Chemical and electrochemical methods such as weight loss (WL) method, potentiodynamic polarization (PP), electrochemical impedance spectroscopy (EIS), and electrochemical frequency modulation (EFM) techniques were utilized to study 1-phenyl-2-pyrazolin-5-one (PPO) derivatives as safe corrosion inhibitors for 304 stainless steel (SS 304) in 1.0 M HCl. The inhibition efficiencies and adsorption characteristics were determined from the WL results. The results indicated that the protection efficiency $(\% I E)$ rises with an increase in the concentration of 1-phenyl-2-pyrazolin-5-one derivatives. The adsorption of these derivatives on the surface of SS 304 follows the Langmuir isotherm. The 1-phenyl-2-pyrazolin-5-one derivatives are good inhibitors for the dissolution of SS 304 in $1 \mathrm{M} \mathrm{HCl}$ and they are mixed-type inhibitors. Analysis of data on the free adsorption energy of 1-phenyl-2-pyrazolin-5-one derivatives on the surface of SS 304 in acid media frequently allows assuming the chemisorption character of their interaction, which to a large extent explains the efficiency of these compounds in corrosion inhibition. At $298 \mathrm{~K}$, atomic force microscopy (AFM) was used to examine the coupon surface morphology without and with inhibitors at a concentration of $24 \cdot 10^{-6} \mathrm{M}$. The development of a protective layer of derivative molecules on the coupon surface in the hydrochloric acid solution at $298 \mathrm{~K}$ is suggested by AFM. Density functional theory (DFT) quantum chemical computations were used to determine the relationship between the electronic structural characteristics of the 1-phenyl-2-pyrazolin-5-one derivative molecules and the inhibitory efficiency. HOMO (highest occupied molecular orbital), LUMO (lowest unoccupied molecular orbital), $E$ (energy gap), $\mu$ (dipole moment), and $A_{0}$ (molecular surface area) were computed. The quantum chemical parameters of the studied inhibitors estimated using the DFT technique accord with the experimental inhibitory efficiency.
\end{abstract}

Received: August 15, 2021. Published: October 8, 2021

doi: $\underline{10.17675 / 2305-6894-2021-10-4-3}$

Keywords: corrosion inhibition, 304 stainless steel, EIS, EFM, SEM, AFM, DFT. 


\section{Introduction}

Stainless steel has high mechanical properties and good corrosion resistance, so it is considered a popular choice among construction materials widely utilized in the majority of manufacturing areas $[1,2]$. The corrosion resistance of these metal alloys has been attributed to an oxide film formed on the surface of SS [3,4]. Nowadays, the dissolution resistance of 304 SS often has to be improved using corrosion protectors. Specifically, the corrosion hindrance of $304 \mathrm{SS}$ in an acid environment with inhibitors is very important as the alloy is often exposed to acids throughout various procedures. The impact of numerous organic inhibitors in corrosion hindrance of $304 \mathrm{SS}$ in the acid environment has been examined $[5,6]$. Organic compounds comprising an $\mathrm{N}, \mathrm{O}, \mathrm{S}$, or P atom (i.e., hetero-atoms), multiple bonds or aromatic systems which can be adsorbed on the surface of an alloy via a lone pair of electrons and/or $\pi$-electrons are frequently confirmed to be remarkably effective inhibitors of dissolution [7,8]. Several 2-pyrazolin-5-one derivatives are known to display diverse pharmacological activities such as analgesics, antipyretics and anticancer agents [9-11]. In this study, the impact of PPO compounds as safe inhibitors for dissolution of 304 SS in $1 \mathrm{M}$ $\mathrm{HCl}$ was tested. The PPO compounds were chosen as corrosion inhibitors because PPO compounds contain multiple active centers and have a distinct affinity to protect SS 304 corrosion in $\mathrm{HCl}$. Finally, several methods, including theoretical and experimental ones, have been used to study the inhibition behavior of PPO compounds against SS 304 corrosion in $1 \mathrm{M} \mathrm{HCl}$.

\section{Materials and Methods}

\section{Materials and solutions}

The SS 304 specimens used for WL and electrochemical tests have the following chemical composition (wt.\%): $0.08 \mathrm{C}, 0.75 \mathrm{Si}, 18-20 \mathrm{Cr}, 2.0 \mathrm{Mn}, 10.5 \mathrm{Ni}, 0.045 \mathrm{P}$ and the rest Fe.

The examined PPO compounds were synthesized according to the procedures demonstrated in previously published papers [9-11]. These compounds are shown in Table 1 . The corrosive solution was prepared by diluting analytical reagent grade $34 \% \mathrm{HCl}$ with distilled water to obtain the desired concentration of $1 \mathrm{M} \mathrm{HCl}$. The $10^{-3} \mathrm{M}$ stock solutions of 2-chlorophenyl hydrazine (PPO) derivatives were dissolved in the smallest amount of dimethyl formamide (DMF) and completed with ethanol and then diluted with distilled water to the final concentrations ranging from $\left(4 \cdot 10^{-6}-24 \cdot 10^{-6} \mathrm{M}\right)$. 
Table 1. The chemical structure of PPO derivatives.

กิ

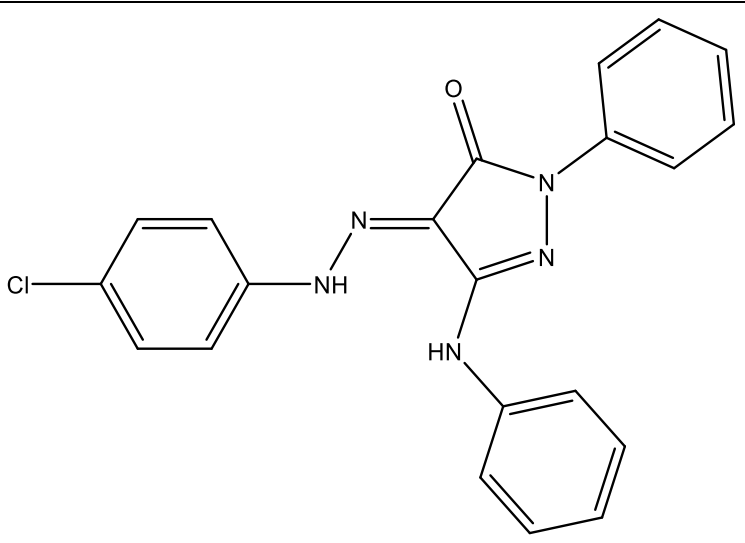

(E)-4-(2-(4-chlorophenyl)hydrazineylidene)-2-phenyl-5-(phenylamino)-2,4-dihydro-3 $H$-pyrazol-3-one Molecular Weight: 389.84

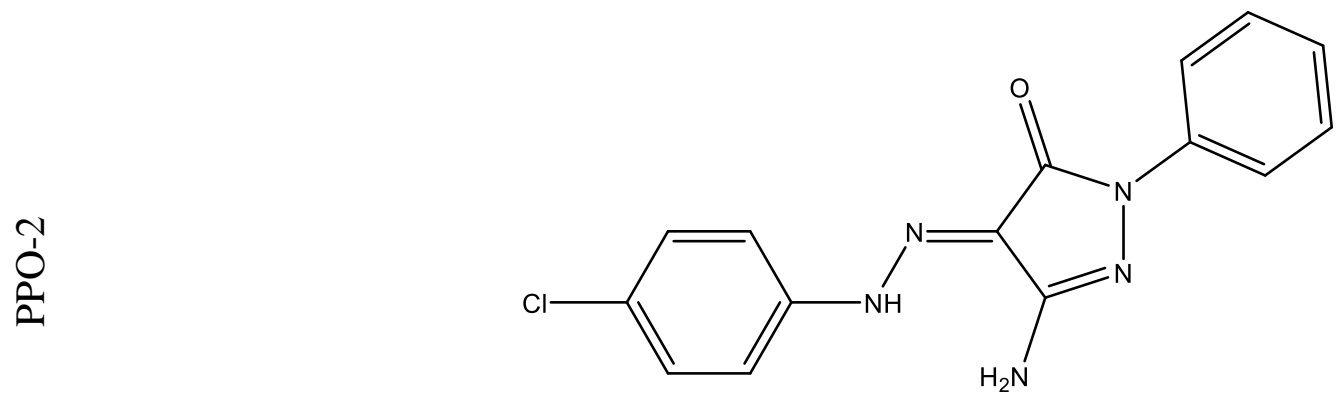

(E)-5-amino-4-(2-(4-chlorophenyl)hydrazineylidene)-2-phenyl-2,4-dihydro-3 $H$ pyrazol-3-one Molecular Weight: 313.75

ô

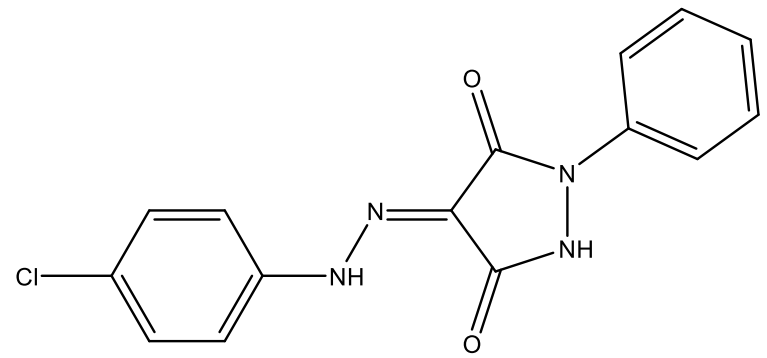

(E)-4-(2-(4-chlorophenyl)hydrazineylidene)-1-phenylpyrazolidine-3,5-dione Molecular Weight: 314.73

\section{Corrosion inhibition evaluation}

\section{WL test}

Samples of 304 stainless with a dimension of $2 \times 2 \times 0.2 \mathrm{~cm}^{3}$ were scratched with various grades of emery papers from 400 to 1200 , rinsed with doubled-distilled water many times, and dried. They were weighed exactly and immersed for $3 \mathrm{~h}$ in a glass bottle (open system) containing $50 \mathrm{ml}$ of $\mathrm{HCl}$ in the presence and in the absence of various concentrations of PPO 
compounds. After every $30 \mathrm{~min}, 304$ SS samples were withdrawn, washed, dried, and weighed thoroughly. The average WL $\left(\mathrm{mg} \cdot \mathrm{cm}^{-2}\right)$ of seven SS 304 coins should be obtained. The degree of surface coverage $(\theta)$ and (\%IE) of PPO for SS 304 dissolution in $1 \mathrm{M} \mathrm{HCl}$ were measured from Equations 1 and 2, respectively:

$$
\begin{aligned}
\theta & =\left[1-\frac{W}{W^{0}}\right] \\
\% I E & =\left[1-\frac{W}{W^{0}}\right] \cdot 100
\end{aligned}
$$

where $W^{0}$ and $W$ are the values of the average WL without and with addition of PPO compounds, respectively.

\section{Electrochemical tests}

All electrochemical measurements were performed in a three-electrode electrochemical cell including an SS 304 working electrode, an $\mathrm{Ag} / \mathrm{AgCl}$ reference electrode, and a platinum disk as the counter electrode. Before each electrochemical test, the SS 304 electrode was dipped for $30 \mathrm{~min}$ in the solution to allow the open circuit potential (OCP) to achieve a steady state. Each experiment was achieved on a freshly abraded electrode utilizing a newly prepared electrolyte.

PP was performed by sweeping the electrode potential from -500 to $500 \mathrm{mV} v s$. (OCP) at a sweep rate of $1 \mathrm{mV} \cdot \mathrm{s}^{-1}$. (\%IE) and $(\theta)$ were determined from $\left(i_{\text {corr }}\right)$ in Equation (3).

$$
\% I E=\theta \cdot 100=\left[1-\frac{i_{\text {corr }}}{i_{\text {corr }}^{0}}\right] \cdot 100
$$

where $i_{\text {corr }}^{0}$ and $i_{\text {corr }}$ are corrosion current densities in the absence and presence of inhibitor, respectively.

EIS tests were carried out by applying AC signals in the range from $100 \mathrm{kHz}$ to $0.1 \mathrm{mHz}$ with a peak amplitude of $5 \mathrm{mV}$ at OCP. All the impedance data were consistent with the suitable equivalent circuit employing the Gamry Echem program, and $(\% I E)$ and $(\theta)$ were measured by utilizing the charge transfer resistance $\left(R_{\mathrm{ct}}\right)$ as a function of the performance of protection.

$$
\% I E=\theta \cdot 100=\left[1-\frac{R_{\mathrm{ct}}^{0}}{R_{\mathrm{ct}}}\right] \cdot 100
$$

where $R_{\mathrm{ct}}^{0}$ and $R_{\mathrm{ct}}$ are the charge-transfer resistance values without and with an inhibitor, respectively.

The EFM technique was utilized by relating two sine waves of 2 and $5 \mathrm{~Hz}[12,13]$. The parameters $\left(i_{\text {corr }}\right), \mathrm{CF}-2$ and CF-3, and $\left(\beta_{\mathrm{c}}\right.$ and $\left.\beta_{\mathrm{a}}\right)$ were measured [14]. $(\theta)$ and $(\% I E)$ were determined from equation (2) like the PP. 
All electrochemical techniques were executed using a Gamry Potentiostat/Galvanostat with PCI4-G750 software for measurements, linked to a PC for data retrieval and storage.

Surface analysis

SS 304 coins were dipped in $1 \mathrm{M} \mathrm{HCl}$ in the presence and in the absence for $24 \cdot 10^{-6} \mathrm{M} \mathrm{PPO}$ compounds for $24 \mathrm{~h}$. The surface morphology of SS 304 stainless coins was studied by Pico SPM2100 for AFM analysis.

Quantum chemical calculations (QM)

QM calculations were performed employing Materials Studio style 7.0 from Accelrys Inc. USA [15-17]. The DMol ${ }^{3}$ model was utilized for QM by relating GGA technique with DNP basis set and BOP functional enclosing COSMO controls [18-21].

\section{Results and Discussion}

\section{WL tests}

The WL plots for SS 304 in $\mathrm{mg} \mathrm{cm} \mathrm{cm}^{-2}$ of the surface area dissolution in $1 \mathrm{M} \mathrm{HCl}$ in the presence and in the absence of various concentrations of PPO1 are displayed in Figure 1. The WLtime lines obtained in the presence of PPO1 are found below that of $1 \mathrm{M} \mathrm{HCl}$ (blank). When the PPO1 concentration rises, WL decreases, $\theta$ rises, and the $\% I E$ improves. The $\% I E$ values are presented in Table 2. This effect results from the adsorption of PPO on SS 304 surface producing a coating layer that separates the SS 304 from the aggressive environment and reduces the 304 stainless steel dissolution. Consequently, the rate of dissolution decreases with an increase in the concentration [22]. The order of \%IE for PPO compounds determined from the calculated values of \%IE is as follows: PPO-1 > PPO-2 > PPO-3.

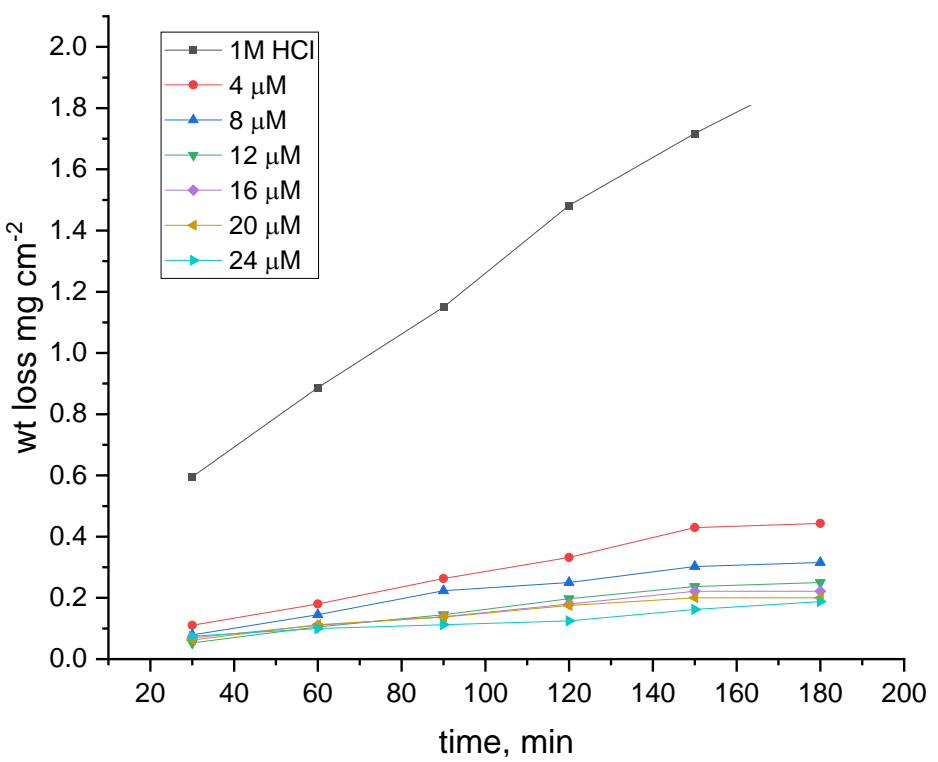

Figure 1. Time-WL diagrams for SS 304 in $1 \mathrm{M} \mathrm{HCl}$ with and without various PPO1 concentrations at $30^{\circ} \mathrm{C}$. 
Table 2. The corrosion rate (C.R.) and (\%IE) for SS304 immersed in $1 \mathrm{M} \mathrm{HCl}$ without and in the presence of PPO derivatives as determined from WL tests at $30^{\circ} \mathrm{C}$.

\begin{tabular}{|c|c|c|c|c|}
\hline Inhibitor & Conc., $\mu \mathrm{M}$ & C.R., $\mathbf{m g} \cdot \mathrm{cm}^{-2} \mathrm{~min}^{-1}$ & $\boldsymbol{\theta}$ & $\% I E$ \\
\hline $1 \mathrm{M} \mathrm{HCl}$ & 0 & 0.0123 & - & - \\
\hline \multirow{6}{*}{ ò } & 4 & 0.0027 & 0.776 & 77.6 \\
\hline & 8 & 0.0020 & 0.831 & 83.1 \\
\hline & 12 & 0.0016 & 0.867 & 86.7 \\
\hline & 16 & 0.0015 & 0.879 & 87.9 \\
\hline & 20 & 0.0014 & 0.882 & 88.2 \\
\hline & 24 & 0.0010 & 0.916 & 91.6 \\
\hline \multirow{6}{*}{ 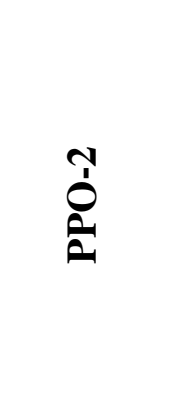 } & 4 & 0.0060 & 0.514 & 51.4 \\
\hline & 8 & 0.0054 & 0.561 & 56.1 \\
\hline & 12 & 0.0051 & 0.583 & 58.3 \\
\hline & 16 & 0.0047 & 0.617 & 61.7 \\
\hline & 20 & 0.0042 & 0.654 & 65.4 \\
\hline & 24 & 0.0035 & 0.710 & 71.0 \\
\hline \multirow{6}{*}{ 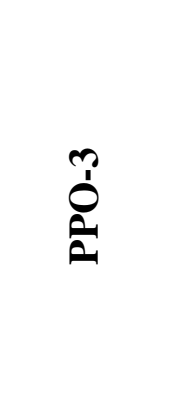 } & 4 & 0.0062 & 0.495 & 49.5 \\
\hline & 8 & 0.0056 & 0.542 & 54.2 \\
\hline & 12 & 0.0049 & 0.600 & 60.0 \\
\hline & 16 & 0.0047 & 0.617 & 61.7 \\
\hline & 20 & 0.0045 & 0.636 & 63.6 \\
\hline & 24 & 0.0041 & 0.663 & 66.3 \\
\hline
\end{tabular}

\section{Adsorption isotherm}

Several trials were performed to fit the experimental data to various isotherms. Various adsorption isotherms were utilized to fit $\theta$ values, including the Frumkin, Langmuir, Temkin, and Freundlich isotherms. It was found that the Langmuir isotherm is the most appropriate isotherm for the data obtained. It can be described by Equation 5 [23]:

$$
\frac{C}{\theta}=\frac{1}{K_{\text {ads }}}+C
$$

Where $C$ is the concentration (M) of the inhibitor in the bulk electrolyte, $\theta$ is the degree of surface coverage, and $K_{\text {ads }}$ is the adsorption equilibrium constant $\left(\mathrm{M}^{-1}\right)$. The linear regressions of $C / \theta$ versus $C$ for PPO are displayed in Figure 2. The $K_{\text {ads }}$ values were 
determined from the intercepts, and the standard free adsorption energies $\left(\Delta G_{\mathrm{ads}}^{0}\right)$ were computed from the $K_{\text {ads }}$ values as follows [24]:

$$
\log K_{\mathrm{ads}}=-\log 55.5-\frac{\Delta G_{\mathrm{ads}}^{0}}{2.303 R T}
$$

where 55.5 is the molar concentration of water in the solution in $\mathrm{mol} / \mathrm{L}, R$ is the gas constant $\left(8.314 \mathrm{~J} \cdot \mathrm{K}^{-1} \mathrm{~mol}^{-1}\right)$, and $T$ is the absolute temperature $(\mathrm{K})$.

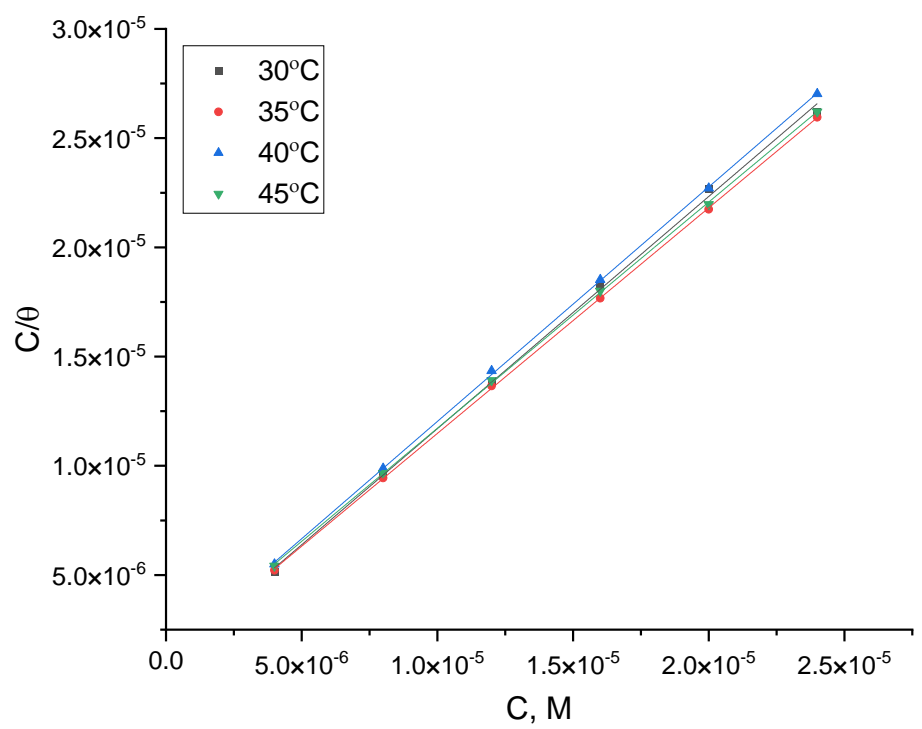

Figure 2. Langmuir plots for the adsorption of PPO-1 on SS 304 in $1 \mathrm{M} \mathrm{HCl}$ at various temperatures.

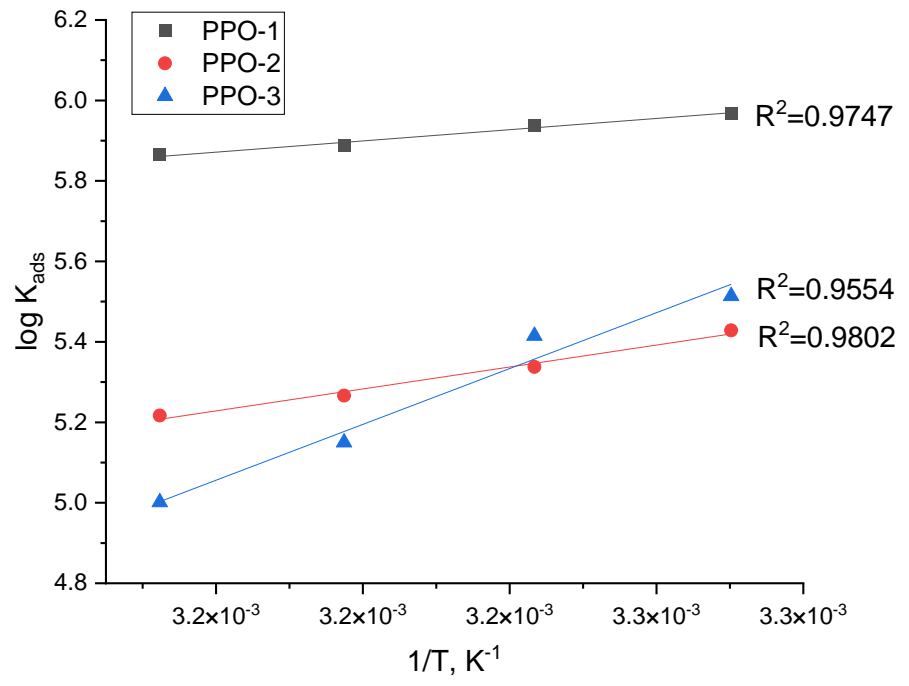

Figure 3. Plots of $\log K_{\text {ads }} v s$. $1 / T$ for corrosion of SS 304 in $1 \mathrm{M} \mathrm{HCl}$ in the absence and presence of various concentrations of PPO derivatives.

The $\Delta G_{\text {ads }}^{0}$ data at all temperatures are presented in Table 3. The $\left(\Delta H_{\text {ads }}^{0}\right)$ values were assessed based on the Van't Hoff Equation: 


$$
\log K_{\mathrm{ads}}=-\frac{\Delta H_{\mathrm{ads}}^{0}}{2.303 R T}+\text { constant }
$$

Table 3. The adsorption isotherm results for dissolution of SS 304 in $1 \mathrm{M} \mathrm{HCl}$ solution in the presence of PPO derivatives at various temperatures.

\begin{tabular}{|c|c|c|c|c|c|}
\hline Inhibitor & Temp, ${ }^{\circ} \mathbf{C}$ & $K_{\text {ads }} \cdot 10^{3} M^{-1}$ & $-\Delta G_{\text {ads }}^{0} \mathbf{k J} \cdot \mathbf{m o l}^{-1}$ & $-\Delta H_{\text {ads }}^{0}, \mathrm{~kJ} \cdot \mathrm{mol}^{-1}$ & $\Delta S_{\text {ads }}^{0}, \mathrm{~J} \mathrm{~mol}^{-1} \mathbf{K}^{-1}$ \\
\hline \multirow{4}{*}{ ò } & 30 & 931.2 & 44.8 & \multirow{4}{*}{13.4} & 103.6 \\
\hline & 35 & 864.7 & 45.3 & & 103.7 \\
\hline & 40 & 771.5 & 45.8 & & 103.5 \\
\hline & 45 & 732.6 & 46.5 & & 403.7 \\
\hline \multirow{4}{*}{ 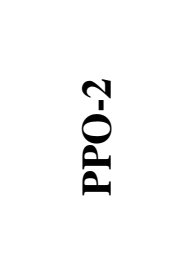 } & 30 & 268.3 & 41.6 & \multirow{4}{*}{26.1} & 51.2 \\
\hline & 35 & 217.7 & 41.8 & & 50.9 \\
\hline & 40 & 184.7 & 42.0 & & 50.9 \\
\hline & 45 & 164.8 & 42.4 & & 51.3 \\
\hline \multirow{4}{*}{$\begin{array}{l}\text { bo } \\
\text { ô }\end{array}$} & 30 & 326.5 & 42.1 & \multirow{4}{*}{66.4} & -80.3 \\
\hline & 35 & 260.1 & 42.2 & & -78.6 \\
\hline & 40 & 141.2 & 41.3 & & -80.2 \\
\hline & 45 & 100.3 & 41.1 & & -79.7 \\
\hline
\end{tabular}

Plotting $\left(\log K_{\text {ads }}\right)$ vs. $(1 / T)$ gives a straight line as demonstrated in Figure 3; the slope is $\left(-\Delta H_{\text {ads }}^{0} / 2.303 R\right)$. The $\Delta H_{\text {ads }}^{0}$ data obtained from this slope are shown in Table 3 . Then by applying the subsequent Equation (8) [25]:

$$
\Delta G_{\mathrm{ads}}^{0}=\Delta H_{\mathrm{ads}}^{0}-T \Delta S_{\mathrm{ads}}^{0}
$$

The data presented in Table 3 confirm the spontaneous adsorption of PPO derivatives on SS304 surfaces. The negative $\Delta G_{\text {ads }}^{0}$ value (spontaneous) greater than $40 \mathrm{~kJ} / \mathrm{mol}$ are indicative of chemical adsorption by creation of coordinate bonds between an active site of PPO (N, O, benzene ring) and empty d-orbitals of iron, or perhaps due to complex formation with $\mathrm{Fe}^{2+}$ ions on SS surface $[26,27]$. The negative sign of $\Delta H_{\text {ads }}^{0}$ for the PPO indicate that the adsorption of PPO compounds is an exothermic process. $\Delta S_{\text {ads }}^{0}$ had a positive sign for PPO-1 and PPO-2 with no noticeable variation at various temperatures, suggesting that PPO molecules adsorption is accompanied by desorption of water molecules from the SS304 surface, which increases the randomness [28]. Moreover, $\Delta S_{\text {ads }}^{0}$ had a negative sign for PPO-3 with no noticeable variation with temperature, suggesting that more inhibitor molecules are arranged on the metal surface than dispersed in solution [29]. 


\section{PP evaluation}

The PP plots for SS 304 dissolution in $1 \mathrm{M} \mathrm{HCl}$ and in the presence and in the absence of various PPO1 concentrations at $25^{\circ} \mathrm{C}$ are demonstrated in Figure 4 . The measured values of $E_{\text {corr }}, i_{\text {corr }}$ from the Tafel curve $\left(i_{\text {corr }}^{0}\right), \theta$ and $\% I E$ are reported in Table 4 [30]. The parallel Tafel lines, $\beta_{\mathrm{a}}$ and $\beta_{\mathrm{c}}$ indicate that both anodic and cathodic mechanisms are not affected by addition of the PPO to the corrosive environment. The data in Table 4 displays that the lower $i_{\text {corr }}$ values in the presence of PPO does not affect considerably the $E_{\text {corr }}$, thus suggesting that the PPO is a mixed kind of inhibitor [31, 32]. The behavior of \%IE for the PPO compound signifies that it hinders both anodic and cathodic reactions on SS304 in $1 \mathrm{M} \mathrm{HCl}$ by protecting the active centers [33]. The order of \%IE for the PPO is: PPO-1>PPO-2>PPO-3, which agrees with the results obtained from weight loss measurements.

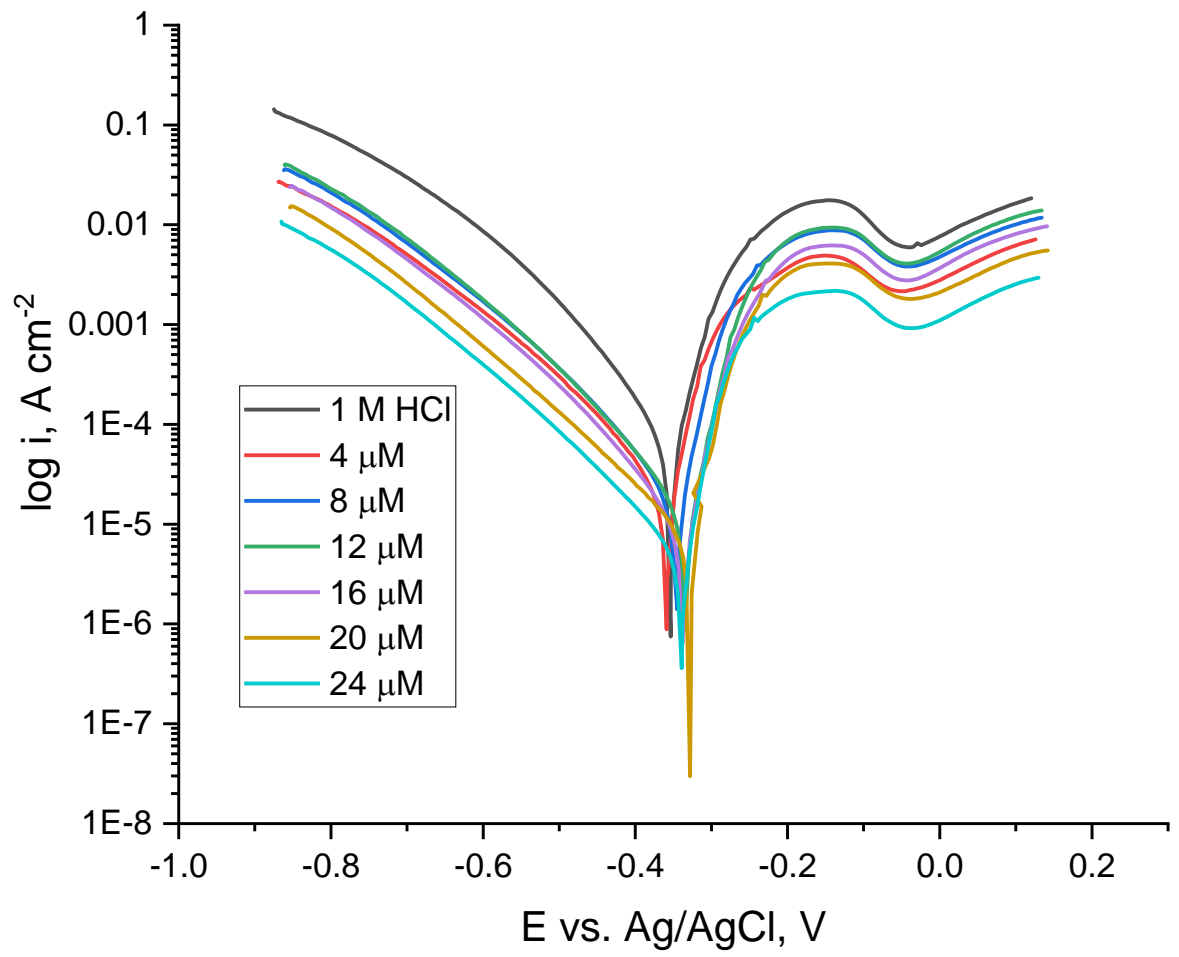

Figure 4. PP for SS 304 in $1 \mathrm{M} \mathrm{HCl}$ without and with various concentrations of PPO-1 at $25^{\circ} \mathrm{C}$. 
Table 4. Polarization results for SS 304 in $1 \mathrm{M} \mathrm{HCl}$ without and with various concentrations of PPO derivatives at $25^{\circ} \mathrm{C}$.

\begin{tabular}{|c|c|c|c|c|c|c|c|c|}
\hline Concentration, & $\mathbf{M}$ & $\begin{array}{c}i_{\text {corr }} \\
\mu \mathrm{Acm}^{-2}\end{array}$ & $\begin{array}{l}-E_{\text {corr, }} \\
\mathrm{mV}\end{array}$ & $\begin{array}{c}b_{\mathrm{a}}, \\
\text { mV/decade }\end{array}$ & $\begin{array}{c}-b_{c} \\
\text { mV/decade }\end{array}$ & C.R., mpy & $\boldsymbol{\theta}$ & $\% I E$ \\
\hline $1 \mathrm{M} \mathrm{HCl}$ & & 71.10 & 354.0 & 46.3 & 105.7 & 32.47 & - & - \\
\hline \multirow{6}{*}{$\begin{array}{l}\overline{1} \\
\grave{a} \\
\text { â }\end{array}$} & 4 & 23.60 & 359.0 & 43.6 & 129.0 & 10.80 & 0.668 & 66.8 \\
\hline & 8 & 20.60 & 346.0 & 40.3 & 127.0 & 9.39 & 0.710 & 71.0 \\
\hline & 12 & 14.80 & 334.0 & 38.8 & 123.6 & 6.76 & 0.792 & 79.2 \\
\hline & 16 & 10.40 & 337.0 & 41.6 & 120.7 & 4.75 & 0.854 & 85.4 \\
\hline & 18 & 8.52 & 328.0 & 37.0 & 145.6 & 3.89 & 0.880 & 88.0 \\
\hline & 20 & 6.20 & 338.0 & 36.3 & 139.1 & 2.59 & 0.913 & 91.3 \\
\hline \multirow{6}{*}{ 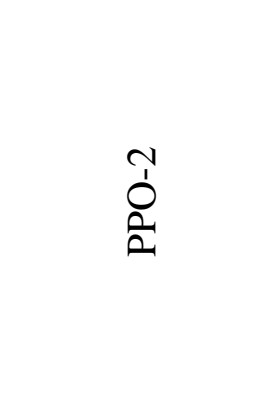 } & 4 & 28.30 & 348.0 & 43.0 & 132.0 & 12.91 & 0.602 & 60.2 \\
\hline & 8 & 23.40 & 334.0 & 40.2 & 129.6 & 10.68 & 0.671 & 67.1 \\
\hline & 12 & 21.40 & 351.0 & 46.9 & 126.2 & 9.76 & 0.699 & 69.9 \\
\hline & 16 & 19.5 & 347.0 & 35.0 & 124.6 & 8.90 & 0.726 & 72.6 \\
\hline & 18 & 17.10 & 345.0 & 35.5 & 127.1 & 7.82 & 0.759 & 75.9 \\
\hline & 20 & 12.80 & 348.0 & 44.3 & 113.5 & 5.82 & 0.820 & 82.0 \\
\hline \multirow{6}{*}{$\begin{array}{l}\hat{0} \\
\hat{0} \\
\hat{2}\end{array}$} & 4 & 35.60 & 354.0 & 53.9 & 128.6 & 16.27 & 0.499 & 49.9 \\
\hline & 8 & 31.40 & 352.0 & 42.4 & 131.8 & 14.32 & 0.558 & 55.8 \\
\hline & 12 & 27.40 & 348.0 & 47.1 & 130.5 & 15.52 & 0.615 & 61.5 \\
\hline & 16 & 25.50 & 346.0 & 40.3 & 128.3 & 11.65 & 0.641 & 64.1 \\
\hline & 18 & 22.90 & 347.0 & 43.9 & 135.5 & 10.47 & 0.678 & 67.8 \\
\hline & 20 & 18.20 & 340.0 & 46.7 & 124.7 & 8.33 & 0.744 & 74.4 \\
\hline
\end{tabular}

\section{Electrochemical impedance measurements}

Figures 5a, b display the Nyquist and Bode plots for SS 304 surface immersed in $1.0 \mathrm{M} \mathrm{HCl}$ in the absence and in the presence of various PPO- 1 concentrations at $25^{\circ} \mathrm{C}$. As the PPO- 1 concentration decreases, the diameter of the semicircle increases [34]. The deviation from the perfect semicircle is normally due to the dispersal of frequencies and the surface's inhomogeneity, grain boundaries, and impurities [35]. Figure 6 displays the equivalent circuit used to fit the EIS spectra for 304 stainless in $1 \mathrm{M} \mathrm{HCl}$ in the presence and in the absence of PPO. The equivalent circuit contains $\left(R_{\mathrm{ct}}\right),\left(R_{\mathrm{s}}\right)$, and $(\mathrm{CPE})$. The impedance $Z_{\mathrm{CPE}}$ can be assessed from the following equation (8) [36]:

$$
Z_{\mathrm{CPE}}=\frac{1}{Y_{0}(j \omega)^{n}}
$$


where $Y_{0}$ is the admittance of the CPE, $j$ is the imaginary number, $\omega$ is the angular frequency and $n$ is the CPE exponent defined as phase shift.
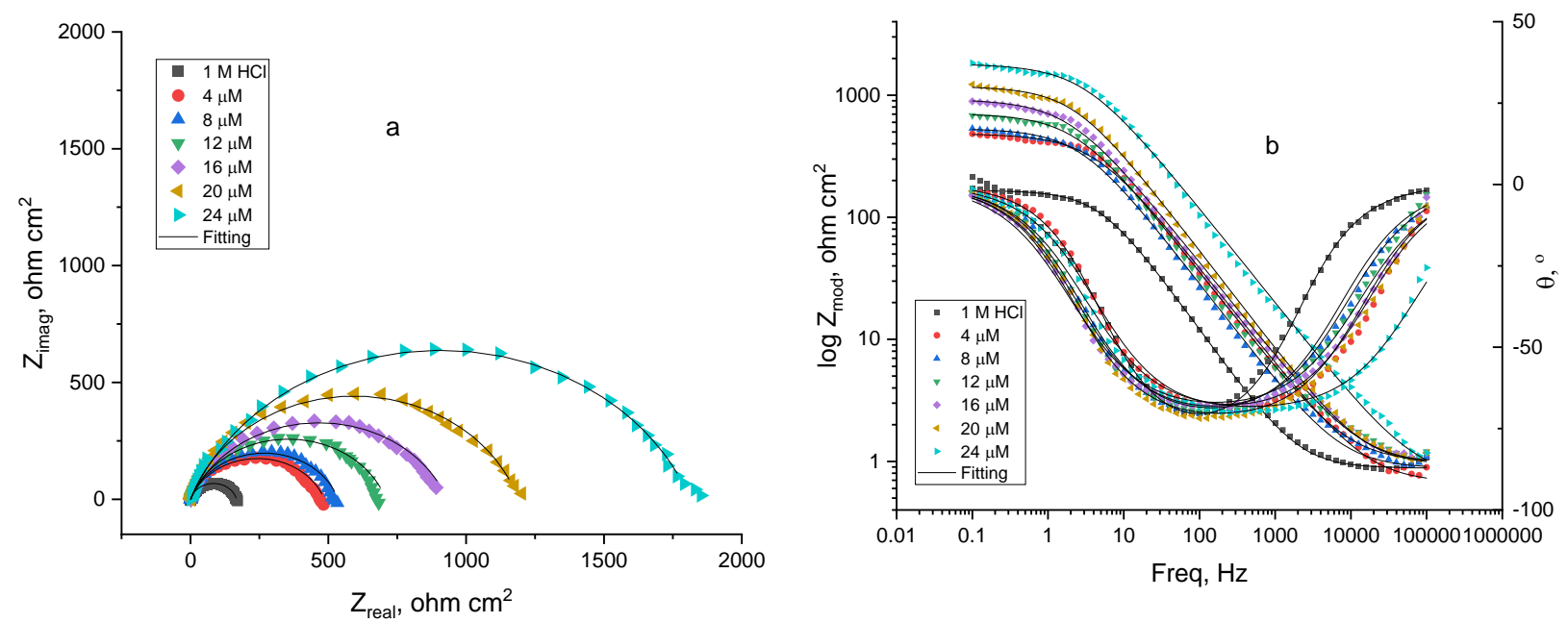

Figure 5. The Nyquist (a) and Bode (b) plots for SS 304 in $1 \mathrm{M} \mathrm{HCl}$ with and without various concentrations of PPO- 1 at $25^{\circ} \mathrm{C}$.

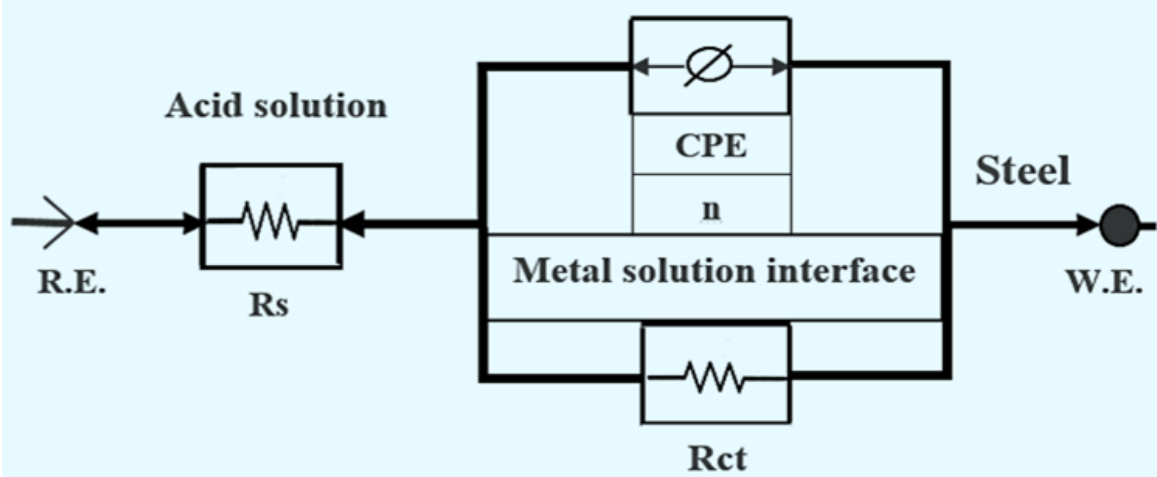

Figure 6. Equivalent electrical circuit utilized to fit the impedance data.

The data of $n$ exponent (Table 5) vary from 0.770 to 0.876 that are representative of non-ideal capacitive behavior, which is assigned to the heterogeneity of 304 stainless surfaces due to the surface roughness [36, 37].

Table 5 reports the EIS parameters. Increasing the concentration of the PPO raises the $\left(R_{\mathrm{ct}}\right)$ owing to an increase in the thickness of the adsorbed layer and lower the $\left(C_{\mathrm{dl}}\right)$ as a result of an increase in the thickness of the electrical double layer or/and a decrease in the dielectric constant due to the substitution of the adsorbed water molecules on 304 stainless steel by PPO molecules, indicating that the PPO molecules function by adsorption at the 304SS/interface [38]. The order of \% IE for PPO is: PPO-1 > PPO-2 > PPO-3, which agrees with the results obtained from WL and PP experiments. 
Table 5. EIS parameters for SS 304 in $1 \mathrm{M} \mathrm{HCl}$ in the absence and in the presence of various concentrations of PPO derivatives at $25^{\circ} \mathrm{C}$.

\begin{tabular}{|c|c|c|c|c|c|c|c|c|}
\hline \multicolumn{2}{|c|}{$\begin{array}{c}\text { Concentration, } \\
\boldsymbol{\mu M}\end{array}$} & $\begin{array}{c}R_{\mathrm{s}}, \\
\mathrm{Ohm} \cdot \mathrm{cm}^{2}\end{array}$ & $\begin{array}{c}R_{\mathrm{ct}} \\
\mathrm{kOhm} \cdot \mathrm{cm}^{2}\end{array}$ & $\begin{array}{c}Y_{0} \\
\mu \operatorname{Ohm}^{\prime} \mathbf{s}^{n} \mathrm{~cm}^{-2}\end{array}$ & $n$ & $C_{\mathrm{dl},} \mu \mathrm{Fcm}^{-2}$ & $\boldsymbol{\theta}$ & $\% I E$ \\
\hline \multicolumn{2}{|c|}{ blank } & 0.88 & 165.6 & 382.7 & 0.872 & 254.9 & - & - \\
\hline \multirow{6}{*}{ 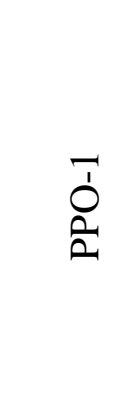 } & 4 & 0.66 & 484.6 & 293.0 & 0.795 & 177.0 & 0.658 & 65.8 \\
\hline & 8 & 0.87 & 534.5 & 187.3 & 0.811 & 109.5 & 0.690 & 69.0 \\
\hline & 12 & 0.98 & 707.9 & 160.6 & 0.801 & 93.4 & 0.766 & 76.6 \\
\hline & 16 & 0.94 & 929.4 & 151.2 & 0.781 & 87.3 & 0.822 & 82.2 \\
\hline & 20 & 0.92 & 1187.0 & 98.0 & 0.815 & 60.0 & 0.860 & 86.0 \\
\hline & 24 & 0.70 & 1812.0 & 54.5 & 0.781 & 28.5 & 0.909 & 90.9 \\
\hline \multirow{6}{*}{$\begin{array}{l}\mathfrak{1} \\
\hat{0} \\
2\end{array}$} & 4 & 1.13 & 380.0 & 261.0 & 0.875 & 187.5 & 0.564 & 56.4 \\
\hline & 8 & 0.93 & 447.1 & 203.4 & 0.876 & 145.0 & 0.630 & 63.0 \\
\hline & 12 & 0.95 & 584.5 & 155.3 & 0.795 & 83.5 & 0.717 & 71.7 \\
\hline & 16 & 1.02 & 608.2 & 142.0 & 0.799 & 76.5 & 0.728 & 72.8 \\
\hline & 20 & 0.99 & 726.9 & 104.5 & 0.802 & 55.4 & 0.772 & 77.2 \\
\hline & 24 & 1.13 & 1051.0 & 97.3 & 0.770 & 49.3 & 0.842 & 84.2 \\
\hline \multirow{6}{*}{$\hat{0}$} & 4 & 0.91 & 325.6 & 291.7 & 0.861 & 199.7 & 0.491 & 49.1 \\
\hline & 8 & 1.05 & 383.70 & 184.7 & 0.842 & 112.6 & 0.568 & 56.8 \\
\hline & 12 & 0.81 & 414.10 & 156.1 & 0.871 & 104.0 & 0.600 & 60.0 \\
\hline & 16 & 0.95 & 519.50 & 153.1 & 0.832 & 91.9 & 0.681 & 68.1 \\
\hline & 20 & 1.30 & 541.00 & 129.5 & 0.818 & 71.5 & 0.694 & 69.4 \\
\hline & 24 & 1.54 & 663.80 & 98.7 & 0.834 & 57.3 & 0.751 & 75.1 \\
\hline
\end{tabular}

Electrochemical frequency modulation (EFM)

The EFM technology is fast and nondestructive. The $i_{\text {corr }}$, causality factors CF- 2 and CF-3, and Tafel slopes $\left(\beta_{\mathrm{a}}\right.$ and $\beta_{\mathrm{c}}$ ) were determined from the higher peaks. The data obtained from EFM for 304 stainless $1 \mathrm{M} \mathrm{HCl}$ with various concentrations of $\mathrm{PPO}$ at $25^{\circ} \mathrm{C}$ were assessed and are recorded in Table 6 . The data show that $i_{\text {corr }}$ decrease with an increase in the concentration of PPO while the \%IE increases. The CF (causality factors) are close to their theoretical values $[39,40]$. The $\% I E$ can be calculated as in Equation 2. The spectra achieved from EFM in the absence and in the presence of various concentrations of PPO-1 are displayed in Figure 7. EFM data are in excellent agreement with the results obtained through the other electrochemical tests. The order of inhibition proficiency for PPO compounds is PPO-1>PPO-2>PPO-3, which agrees with the results obtained from WL, PP, and EIS experiments. 
Table 6. Electrochemical parameters obtained by EFM technique for SS 304 in $1 \mathrm{M} \mathrm{HCl}$ without and with different concentrations of PPO derivatives at $25^{\circ} \mathrm{C}$.

\begin{tabular}{|c|c|c|c|c|c|c|c|c|c|}
\hline \multicolumn{2}{|c|}{ Conc., mM } & $\begin{array}{c}i_{\mathrm{corr}} \\
\mu \mathrm{A} \mathrm{cm}^{-2}\end{array}$ & $\begin{array}{c}b_{\mathrm{a}}, \\
\text { mV/decade }\end{array}$ & $\begin{array}{c}-b_{c} \\
\text { mV/decade }\end{array}$ & $\begin{array}{l}\text { C.R., } \\
\text { mpy }\end{array}$ & CF-2 & CF-3 & $\boldsymbol{\theta}$ & $\% I E$ \\
\hline \multicolumn{2}{|c|}{ blank } & 98.04 & 85.1 & 94.9 & 44.77 & 2.417 & 2.670 & - & - \\
\hline \multirow{6}{*}{$\begin{array}{l}7 \\
\text { 仓े } \\
\text { â }\end{array}$} & 4 & 35.03 & 80.0 & 99.9 & 15.99 & 1.814 & 3.123 & 0.643 & 64.3 \\
\hline & 8 & 30.50 & 84.1 & 106.2 & 13.90 & 1.973 & 2.895 & 0.689 & 68.9 \\
\hline & 12 & 25.02 & 81.8 & 103.9 & 11.42 & 1.602 & 2.806 & 0.745 & 74.5 \\
\hline & 16 & 23.01 & 62.8 & 77.5 & 10.51 & 1.895 & 3.014 & 0.765 & 76.5 \\
\hline & 20 & 13.03 & 75.2 & 94.2 & 5.95 & 1.770 & 2.951 & 0.867 & 86.7 \\
\hline & 24 & 9.48 & 77.9 & 101.0 & 4.33 & 1.833 & 3.031 & 0.903 & 90.3 \\
\hline \multirow{6}{*}{ 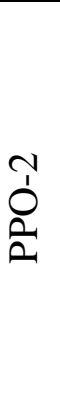 } & 4 & 41.27 & 70.8 & 88.0 & 18.85 & 2.170 & 3.014 & 0.579 & 57.9 \\
\hline & 8 & 35.44 & 75.5 & 111.7 & 16.18 & 1.862 & 2.984 & 0.639 & 63.9 \\
\hline & 12 & 31.31 & 81.7 & 112.3 & 14.30 & 1.918 & 3.011 & 0.681 & 68.1 \\
\hline & 16 & 28.22 & 80.1 & 108.3 & 12.89 & 1.944 & 3.035 & 0.712 & 71.2 \\
\hline & 20 & 25.55 & 75.1 & 103.2 & 11.67 & 1.956 & 3.068 & 0.739 & 73.9 \\
\hline & 24 & 19.37 & 76.2 & 97.2 & 8.84 & 1.862 & 3.025 & 0.802 & 80.2 \\
\hline \multirow{6}{*}{$\begin{array}{l}n \\
\hat{0} \\
\hat{2}\end{array}$} & 4 & 51.28 & 84.2 & 106.0 & 23.42 & 1.982 & 3.040 & 0.477 & 47.7 \\
\hline & 8 & 45.59 & 78.5 & 103.8 & 20.82 & 1.968 & 2.950 & 0.535 & 53.5 \\
\hline & 12 & 39.01 & 82.3 & 125.7 & 17.81 & 1.974 & 2.770 & 0.602 & 60.2 \\
\hline & 16 & 36.01 & 77.5 & 107.1 & 16.44 & 1.750 & 2.860 & 0.633 & 63.3 \\
\hline & 20 & 33.06 & 74.7 & 106.5 & 15.09 & 1.984 & 3.020 & 0.663 & 66.3 \\
\hline & 24 & 26.03 & 78.1 & 125.1 & 11.89 & 1.845 & 3.018 & 0.734 & 73.4 \\
\hline
\end{tabular}

Surface analysis

Figure $8 \mathrm{a}-\mathrm{e}$ displays the 2D and 3D AFM morphology for 304 stainless surfaces before and after immersion in $1 \mathrm{M} \mathrm{HCl}$ in the absence and in the presence of $24 \cdot 10^{-6} \mathrm{M}$ of PPO compounds. Figure 8a shows that the AFM image of polished 304 stainless surfaces (bare metal) seems smooth, with a small roughness $(28.22 \mathrm{~nm})$. Immersion in $\mathrm{HCl}$ (blank) for $24 \mathrm{~h}$ results in dissolution and the roughness of 304 stainless rises $(382.86 \mathrm{~nm})$ as shown in Figure $8 \mathrm{~b}$. After $24 \mathrm{~h}$ of dissolution, no pitting was detected on the 304 stainless steel in the presence of $24 \cdot 10^{-6} \mathrm{M}$ of PPO, and the surface roughness decreased $(92.41,164.18,180.67$ $\mathrm{nm}$ ) in comparison with the blank sample as demonstrated in Figure 8c-e. The 304 stainless coins are smoothed by the adsorbed surface layers of the PPO [41]. 

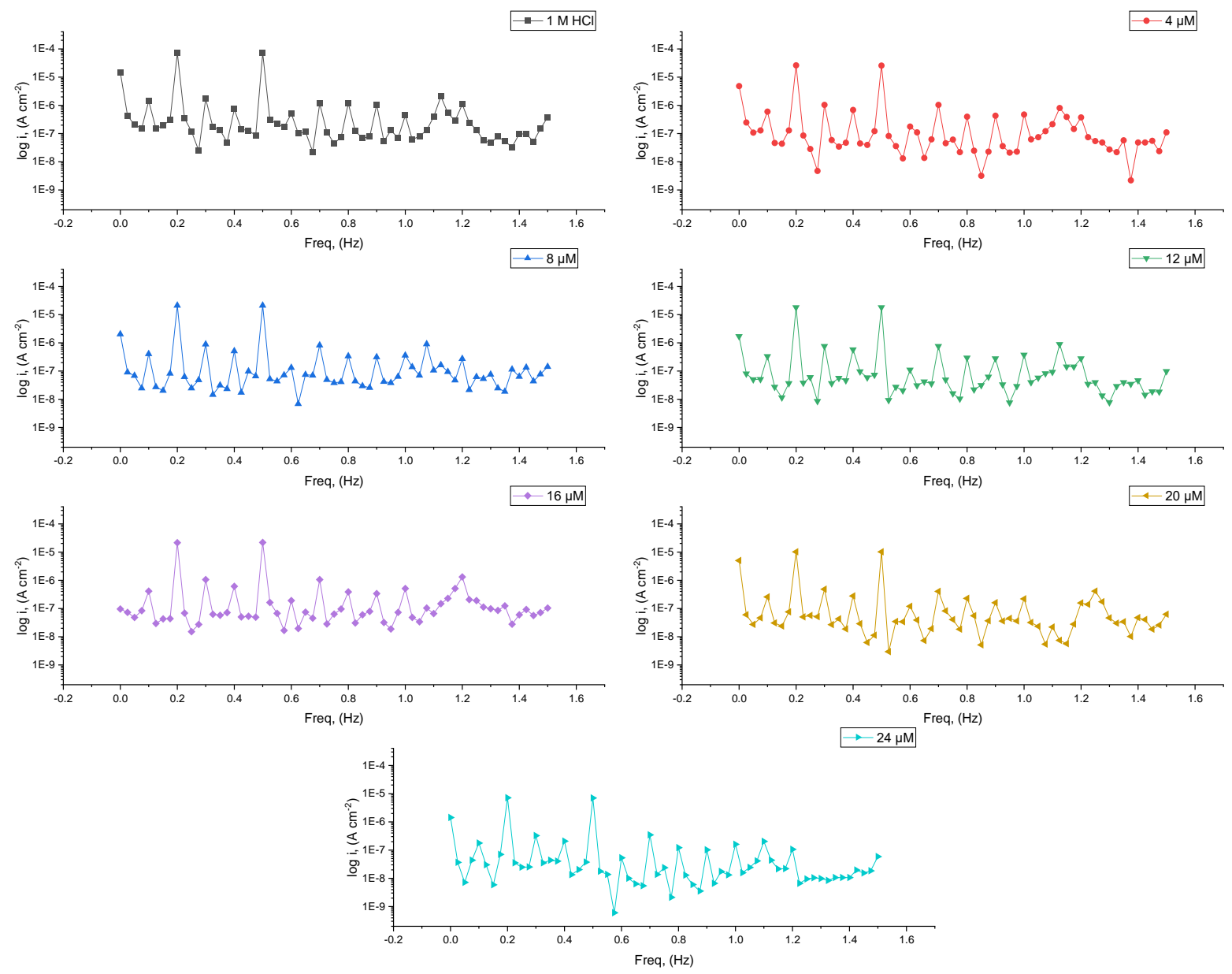

Figure 7. EFM graphs for SS 304 in $1 \mathrm{M} \mathrm{HCl}$ with and without various concentrations of PPO- 1 at $25^{\circ} \mathrm{C}$.

\section{Quantum chemical calculations (QM)}

The relationship between the molecular structure of PPO and its protective action was described via QM. Table 7 demonstrates the quantum chemical parameters calculated for PPO molecules, particularly $E_{\mathrm{LUMO}}, \mathrm{E}_{\mathrm{HOMO}}, \Delta E$, and $\mu$. Figure 9 demonstrates the optimized structure, HOMO, and LUMO for PPO molecules.

The HOMO of PPO molecules is mostly located on N, O, and phenyl pyrazolidine moiety, which favors the electron-donating from PPO molecules to the 304 stainless (Figure 9). PPO-1 has the highest $E_{\mathrm{HOMO}}$, hence, the best corrosion inhibition action was shown by PPO-1 (-4.496 eV) compared with PPO-2 $(-4.986 \mathrm{eV})$ and PPO-3 $(-5.118 \mathrm{eV})$. Generally, the smaller the $\Delta E$ value, the more simple it is to donate electrons and the better the adsorption on 304 stainless steel surface [42]. Therefore, the lowest $\Delta E$ value for PPO-1 molecule $(1.305 \mathrm{eV})$ favors the adsorption and improves the \%IE (Table 7).

Table 7 demonstrates the highest dipole moment for PPO-1 molecule (9.667 Debye), which indicates an IE rise [43-45]. Additionally, the PPO-1 molecule has the highest surface area $\left(397.269 \AA^{2}\right)$, which raises the interaction area among the PPO-1 molecule and the 
surface of 304 stainless steel or increases the area of 304 stainless steel coated with a molecule.

2D

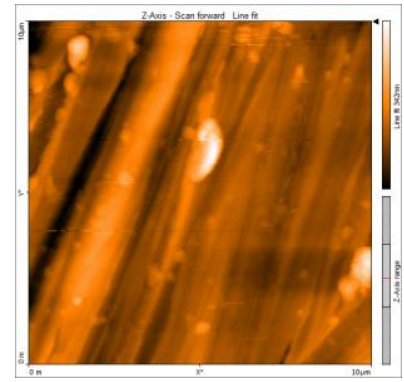

(a) Free
3D

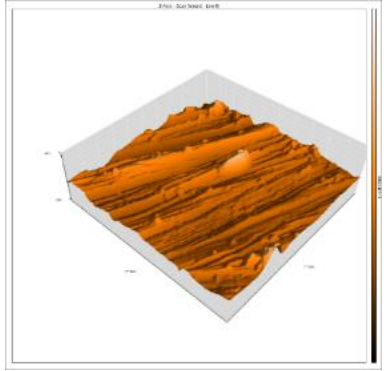

(a) Free

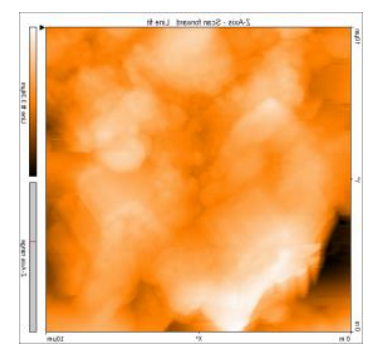

(b) 1 M HCl

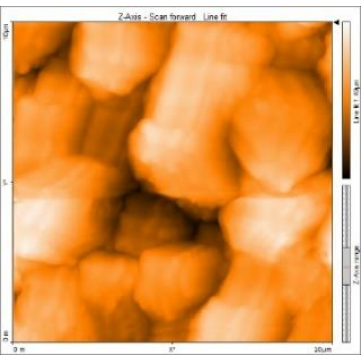

(d) $1 \mathrm{M} \mathrm{HCl}+24 \cdot 10^{-6} \mathrm{M}$ PPO-2

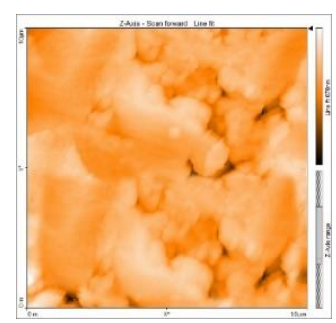

(c) $1 \mathrm{M} \mathrm{HCl}+24 \cdot 10^{-6} \mathrm{M}$ PPO-1

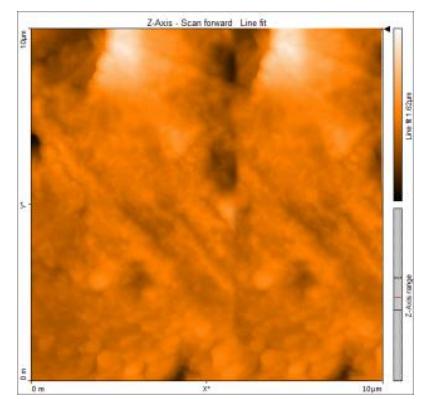

(e) $1 \mathrm{M} \mathrm{HCl}+24 \cdot 10^{-6} \mathrm{M}$

PPO-3

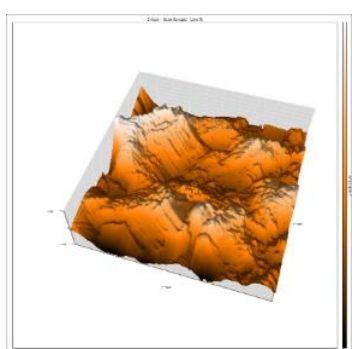

(b) $1 \mathrm{M} \mathrm{HCl}$

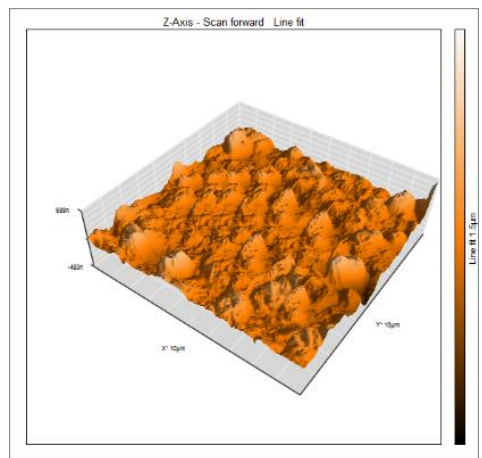

(d) $1 \mathrm{M} \mathrm{HCl}+24 \cdot 10^{-6} \mathrm{M}$

PPO-2

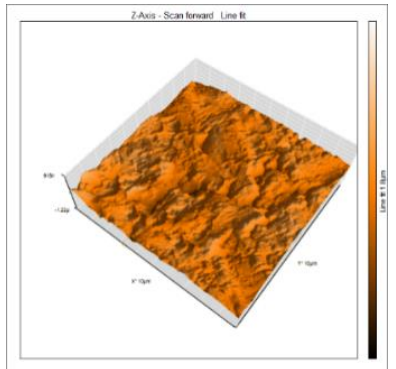

(c) $1 \mathrm{M} \mathrm{HCl}+24 \cdot 10^{-6} \mathrm{M}$ PPO-1

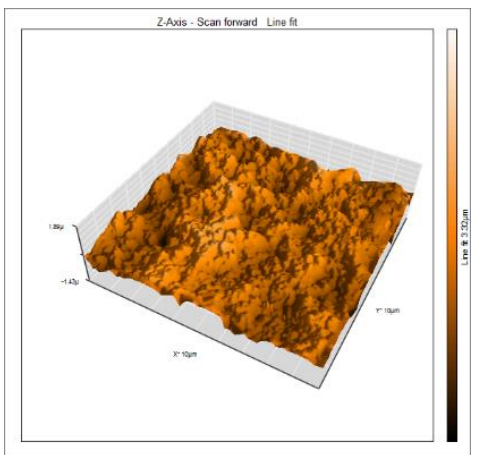

(e) $1 \mathrm{M} \mathrm{HCl}+24 \cdot 10^{-6} \mathrm{M}$ PPO-3

Figure 8. 2D and 3D AFM images of the SS 304 surface (a) before exposure in $1 \mathrm{M} \mathrm{HCl}$ solution, (b) after immersion in $1 \mathrm{M} \mathrm{HCl}$ for $24 \mathrm{~h}$, and (c-e) after immersion in $1 \mathrm{M} \mathrm{HCl}$ with addition of $24 \cdot 10^{-6} \mathrm{M}$ of PPO derivatives for $24 \mathrm{~h}$ at $25^{\circ} \mathrm{C}$. 
HOMO
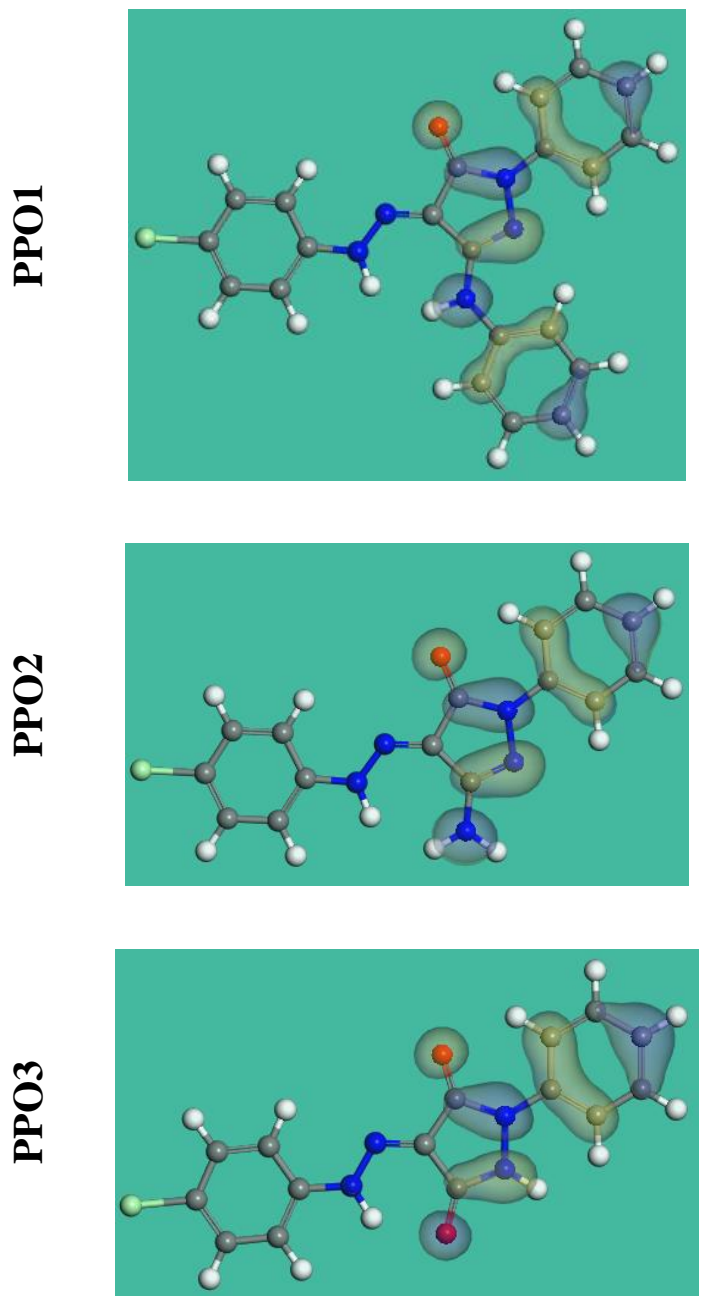

LUMO
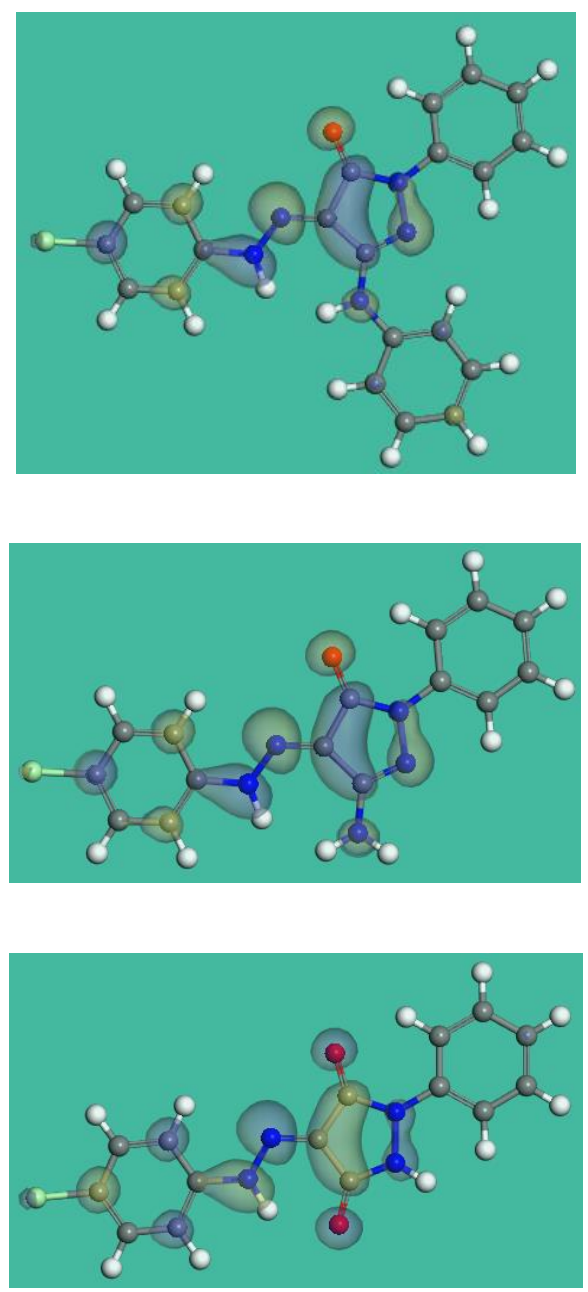

Figure 9. The HOMO and LUMO of the PPO molecules using $\mathrm{DMol}^{3}$.

Table 7. The calculated quantum chemical parameters for PPO derivatives utilizing $\mathrm{DMol}^{3}$.

\begin{tabular}{cccc}
\hline & PPO-1 & PPO-2 & PPO-3 \\
\hline $\boldsymbol{E}_{\text {номо }}, \mathbf{e V}$ & -4.496 & -4.986 & -5.118 \\
\hline $\boldsymbol{E}_{\text {LUMO }}, \mathbf{e V}$ & -3.191 & -2.87 & -2.935 \\
\hline $\boldsymbol{\Delta} \boldsymbol{E}=\boldsymbol{E}_{\mathrm{LUMO}}-\boldsymbol{E}_{\text {HOMO }}, \mathbf{e V}$ & 1.305 & 2.116 & 2.183 \\
\hline Dipole moment, Debye & 9.667 & 5.296 & 4.572 \\
\hline Molecular surface area, $\AA^{2}$ & 397.269 & 322.300 & 315.066 \\
\hline
\end{tabular}




\section{Mechanism of inhibition}

Based on the results obtained from chemical and electrochemical studies, the protection mechanism of PPO could be assumed. The examined PPO molecules can be converted to a cation (protonated form) in an acid medium. The protonated PPO molecules have various active centers, which are the $\mathrm{N}, \mathrm{O}$ atoms, and $\pi$-orbitals of benzene [46]. Hence, the inhibitive properties of the PPO may be achieved by the contribution of two types of interaction: (a) Electrostatic attraction (physical adsorption) between the protonated PPO particles (positive charge) and the cathodic destinations of SS surface (negative charge). Furthermore, electrostatic association between the Cl-particles (negative charge) and the anodic destinations of SS surface (positive charge), (b) Chemical attraction (chemisorption) between the $\mathrm{N}^{+}$molecule and $\pi$-orbitals of benzene rings, unpaired electrons of $\mathrm{N}, \mathrm{O}$ atoms, and the vacant d-orbitals of iron surface molecules. In this way, using multiple sites of adsorptions, PPO molecules can adhere strongly to 304 stainless steel surface [46]. These methods of association are consistent with the estimated $\Delta G_{\text {ads }}^{0}$ values, hence PPO undergoes chemisorption.

\section{Conclusions}

Based on the experimental and theoretical results, we can assume that the PPO derivatives are good inhibitors for the protection of 304 stainless steel from dissolution in the acid environment. Furthermore, the \%IE of PPO derivatives raises with concentration and the PPO molecules adsorbed on the surface of 304 stainless diminish the $C_{\mathrm{dl}}$ values in the presence of the PPO derivatives in comparison with a blank solution, as also confirmed by AFM tests. Moreover, the adsorption of the PPO derivatives on 304 stainless steel in $1 \mathrm{M}$ $\mathrm{HCl}$ is found to be chemisorption and is described by the Langmuir isotherm. Finally, the \%IE for 304 stainless steel surfaces utilizing PPO derivatives in $1 \mathrm{M} \mathrm{HCl}$ is confirmed by both experimental and theoretical approaches.

\section{Funding}

This research received no external funding.

\section{Conflicts of Interest}

The authors declare no conflict of interest.

\section{References}

1. R. Wang and M. Kido, Influence of input power to vibrator and vibrator-to-specimen distance of ultrasound on pitting corrosion of SUS304 stainless steel in 3.5\% chloride sodium aqueous solution, Corros. Sci., 2009, 51, 1604-1610. doi: $\underline{10.1016 / j . c o r s c i .2009 .04 .007}$ 
2. Y.L. Huang, C.N. Cao, M. Lu and H.C. Lin, Inhibition effects of $\mathrm{I}^{-}$and $\mathrm{I}_{2}$ on stress corrosion cracking of stainless steel in acidic chloride solutions, Corrosion, 1993, 49, 644-649. doi: $\underline{\text { 10.5006/1.3316095 }}$

3. A. Pardo, E. Otero, M.C. Merino, M.D. López, M.V. Utrilla and F. Moreno, Influence of $\mathrm{pH}$ and chloride concentration on the pitting and crevice corrosion behavior of highalloy stainless steels, Corrosion, 2000, 56, 411-418. doi: 10.5006/1.3280545

4. A.S. Fouda, M.A. El-Morsy, A.A. El-Barbary and L.E. Lamloum, Study on corrosion inhibition efficiency of some quinazoline derivatives on stainless steel 304 in hydrochloric acid solutions, Int. J. Corros. Scale Inhib., 2016, 5, 112-131. doi: 10.17675/2305-6894-2016-5-2-2

5. N. Goudarzi, M. Peikari, M.R. Zahri and H.R. Mousavi, Adsorption and corrosion inhibition behavior of stainless steel 316 by aliphatic amine compounds in acidic solution, Arch. Metall. Mater., 2012, 57, 845-851. doi: 10.2478/v10172-012-0044-1

6. N. Goudarzi and H. Farahani, Investigation on 2-mercaptobenzothiazole behavior as corrosion inhibitor for 316-stainless steel in acidic media, Anti-Corrosion Methods and Mater., 2014, 61, 20-26. doi: 10.1108/ACMM-11-2012-1223

7. S.K. Saha, A. Dutta, P. Ghosh, D. Sukul and P. Banerjee, Novel Schiff-base molecules as efficient corrosion inhibitors for mild steel surface in $1 \mathrm{M} \mathrm{HCl}$ medium: experimental and theoretical approach, Phys. Chem. Chem. Phys., 2016, 18, 17898-17911. doi: 10.1039/C6CP01993E

8. L.O. Olasunkanmi and E.E. Ebenso, Experimental and computational studies on propanone derivatives of quinoxalin-6- yl-4,5-dihydropyrazole as inhibitors of mild steel corrosion in hydrochloric acid, J. Colloid Interface Sci., 2020, 561, 104-116. doi: 10.1016/j.jcis.2019.11.097

9. H.A. Etman, E.G. Sadek and M.A. Metwally, New route for the synthesis of N-alkyl-2(phenylsulfonyl)anilines, Chem. Heterocycl. Compd., 2016, 52, 570-573. doi: 10.1007/s10593-016-1933-4

10. S.A.M. Metwally, T.A. Mohamed, O.S. Moustafa and Y.A. El-Ossaily, Novel synthesis of highly functionalized pyrazolone systems via rearrangement of 5-phenyl-1-oxa-5,6diazaspiro [2.4]heptane-4,7-diones, Chem. Heterocycl. Compd., 2011, 46, 1344-1353. doi: $10.1007 / \mathrm{s} 10593-011-0671-\mathrm{x}$

11. U.P. Singh, H.R. Bhat, A. Verma, M.K. Kumawat, R. Kaur, S.K. Gupta and R.K. Singh, Phenyl hydrazone bearing pyrazole and pyrimidine scaffolds: Design and discovery of a novel class of non-nucleoside reverse transcriptase inhibitors (NNRTIs) against HIV-1 and their antibacterial properties, $R S C A d v ., 2013$, 3, 17335-17348. doi: $\underline{10.1039 / \mathrm{c} 3 \mathrm{ra} 41604 \mathrm{f}}$

12. K.F. Khaled, Evaluation of electrochemical frequency modulation as a new technique for monitoring corrosion and corrosion inhibition of carbon steel in perchloric acid using hydrazine carbodithioic acid derivatives, J. Appl. Electrochem., 2009, 39, 429-438. doi: 10.1007/s10800-008-9688-y 
13. W. Li, Z. Zhang, Y.Zhai, L. Ruan, W. Zhang and L. Wu, Electrochemical and Computational Studies of Proline and Captopril as Corrosion Inhibitors on Carbon Steel in a Phase Change Material Solution, Int. J. Electrochem. Sci., 2020, 15, 722-739. doi: $10.20964 / 2020.01 .63$

14. D.K. Lavanya, F.V. Priya and D.P. Vijaya, Green Approach to Corrosion Inhibition of Mild Steel in Hydrochloric Acid by 1-[Morpholin-4-yl(thiophen-2-yl) methyl]thiourea. J. Fail. Anal. Prev., 2020, 20, 494-502. doi: 10.1007/s11668-020-00850-9

15. Y.M. Abdallah, K. Shalabi and N.M. Bayoumy, Eco-friendly synthesis, biological activity and evaluation of some new pyridopyrimidinone derivatives as corrosion inhibitors for API 5L X52 carbon steel in 5\% sulfamic acid medium, J. Mol. Struct., 2018, 1171, 658-671. doi: 10.1016/j.molstruc.2018.06.045

16. A.S. Fouda, G.Y. El-Awady and W.T. El Behairy, Prosopis juliflora Plant Extract as Potential Corrosion Inhibitor for Low-Carbon Steel in $1 \mathrm{M} \mathrm{HCl} \mathrm{Solution,} \mathrm{J.} \mathrm{Bio-} \mathrm{Tribo-}$ Corrosion., 2017, 4. doi: 10.1007/s40735-017-0124-X

17. S.S.A. Rehim, O.A. Hazzazi, M.A. Amin and K.F. Khaled, On the corrosion inhibition of low carbon steel in concentrated sulphuric acid solutions. Part I: Chemical and electrochemical (AC and DC) studies, Corros. Sci., 2008, 50, 2258-2271. doi: 10.1016/j.corsci.2008.06.005

18. A.S. Fouda, S.A. Abd El-Maksoud and A. El-Hossiany, A. Ibrahim, Corrosion Protection of Stainless Steel 201 in Acidic Media using Novel Hydrazine Derivatives as Corrosion Inhibitors, Int. J. Electrochem. Sci., 2019, 14, 2187-2207. doi: $\underline{10.20964 / 2019.03 .15}$

19. K. Shimizu, A. Lasia and J.-F. Boily, Electrochemical Impedance Study of the Hematite/Water Interface, Langmuir, 2012, 28, 7914-7920. doi: 10.1021/la300829c

20. R.W. Bosch, J. Hubrecht, W.F. Bogaerts and B.C. Syrett, Electrochemical Frequency Modulation: A New Electrochemical Technique for Online Corrosion Monitoring, Corrosion, 2001, 57, 60-70. doi: 10.5006/1.3290331

21. A.H. El-Askalany, S.I. Mostafa, K. Shalabi, A.M. Eid and S. Shaabana, Novel tetrazolebased symmetrical diselenides as corrosion inhibitors for $\mathrm{N} 80$ carbon steel in $1 \mathrm{M} \mathrm{HCl}$ solutions: Experimental and theoretical studies, J. Mol. Liq., 2016, 223, 497-508, doi: 10.1016/j.molliq.2016.08.088

22. A.S. Fouda, M. Abdel Azeem, S.A. Mohamed, A. El-Hossiany and E. El-Desouky, Corrosion Inhibition and Adsorption Behavior of Nerium Oleander Extract on Carbon Steel in Hydrochloric Acid Solution, Int. J. Electrochem. Sci., 2019, 14, 3932-3948. doi: 10.20964/2019.04.44

23. F. Bentiss, M. Bouanis, B. Mernari, M. Traisnel, H. Vezin and M. Lagrenée, Understanding the adsorption of $4 \mathrm{H}-1,2,4$-triazole derivatives on mild steel surface in molar hydrochloric acid, Appl. Surf. Sci., 2007, 253, 3696-3704. doi: $\underline{10.1016 / j . a p s u s c .2006 .08 .001}$ 
24. L. Elkadi, B. Mernari, M. Traisnel, F. Bentiss and M. Lagrenée, The inhibition action of 3,6-bis(2-methoxyphenyl)-1,2-dihydro-1,2,4,5-tetrazine on the corrosion of mild steel in acidic media, Corros. Sci., 2000, 42, 703-719. doi: 10.1016/S0010-938X(99)00101-8

25. A.K. Singh and M.A. Quraishi, Investigation of the effect of disulfiram on corrosion of mild steel in hydrochloric acid solution, Corros. Sci., 2011, 53, 1288-1297. doi: 10.1016/j.corsci.2011.01.002

26. A.S. Fouda, S. Rashwan, A. El-Hossiany and F.E. El-Morsy, Corrosion Inhibition of Zinc in Hydrochloric Acid Solution using some organic compounds as Eco-friendly Inhibitors, J. Chem. Biol. Phys. Sci., 2019, 9, 1-24. doi: 10.24214/jcbps.A.9.1.00124

27. H.A. Sorkhabi, B. Shaabani and D. Seifzadeh, Corrosion inhibition of mild steel by some Schiff base compounds in hydrochloric acid, App. Surf. Sci., 2005, 239, 154-164. doi: 10.1016/j.apsusc.2004.05.143

28. R. Hsissou, S. Abbout, A. Berisha, M. Berradi, M. Assouag, N. Hajjaji and A. Elharfi, Experimental, DFT and molecular dynamics simulation on the inhibition performance of the DGDCBA epoxy polymer against the corrosion of the E24 carbon steel in $1.0 \mathrm{M}$ HCl solution, J. Mol. Struct., 2019, 1182, 340-351. doi: 10.1016/j.molstruc.2018.12.030

29. M. Arivazhagan and V.P. Subhasini, Quantum chemical studies on structure of 2-amino5-nitropyrimidine, Spectrochim. Acta, Part A, 2012, 91, 402-410. doi: 10.1016/j.saa.2012.02.018

30. A.S. Fouda, S.A. Abd El-Maksoud, A. El-Hossiany and A. Ibrahim, Effectiveness of Some Organic Compounds as Corrosion Inhibitors for Stainless Steel 201 in 1M HCl: Experimental and Theoretical Studies, Int. J. Electrochem. Sci., 2018, 13, 9826-9846. doi: $10.20964 / 2018.10 .36$

31. R.A. Prabhu, T.V. Venkatesha, A.V. Shanbhag, G.M. Kulkarni and R.G. Kalkhambkar, Inhibition effects of some Schiff's bases on the corrosion of mild steel in hydrochloric acid solution, Corros. Sci., 2008, 50, 3356-3362. doi: 10.1016/j.corsci.2008.09.009

32. K.M. Shainy, P.R. Ammal, K.N. Unni, S. Benjamin and A. Joseph, Surface Interaction and Corrosion Inhibition of Mild Steel in Hydrochloric Acid Using Pyoverdine, an EcoFriendly Bio-molecule, J. Bio- and Tribo-Corrosion, 2016, 2. doi: 10.1007/s40735-0160050-3

33. A.R. El-Sayed, H.S. Mohran and H.M. Abd El-Lateef, The inhibition effect of 2,4,6-tris (2-pyridyl)-1,3,5-triazine on corrosion of tin, indium and tin-indium alloys in hydrochloric acid solution, Corros. Sci., 2010, 52, 1976-1984. doi: 10.1016/j.corsci.2010.02.029

34. A.S. Fouda, S.A. Abd El-Maksoud, A. El-Hossiany and A. Ibrahim, Evolution of the Corrosion-inhibiting Efficiency of Novel Hydrazine Derivatives against Corrosion of Stainless Steel 201 in Acidic Medium, Int. J. Electrochem. Sci., 2019, 14, 6045-6064. doi: $10.20964 / 2019.07 .65$

35. M.A. Bidi, M. Azadi and M. Rassouli, new green inhibitor for lowering the corrosion rate of carbon steel in $1 \mathrm{M} \mathrm{HCl}$ solution: Hyalomma tick extract, Mater. Today Commun., 2020, 24, 1-9. doi: 10.1016/j.mtcomm.2020.100996 
36. B.S. Hou, Q.H. Zhang, Y.Y. Li, G.Y.Zhu, H.F. Liu and G.A. Zhang, A pyrimidine derivative as a high efficiency inhibitor for the corrosion of carbon steel in oilfield produced water under supercritical CO2 conditions, Corros. Sci., 2020, 164, 1-18. doi: 10.1016/j.corsci.2019.108334

37. D. Gopi, K.M. Govindaraju and L. Kavitha, Investigation of triazole steel derived Schiff bases as corrosion inhibitors for mild steel in hydrochloric acid medium, J. Appl. Electrochem., 2010, 40, 1349-1356. doi: 10.1007/s10800-010-0092-Z

38. M.M. Motawea, A. El-Hossiany and A.S. Fouda, Corrosion Control of Copper in Nitric Acid Solution using Chenopodium Extract, Int. J. Electrochem. Sci., 2019, 14, 1372-1387. doi: $10.20964 / 2019.02 .29$

39. W. Emori, R.H. Zhang, P.C. Okafor, X.W. Zheng, T. He, K. Wei, X.Z. Lin and C.R. Cheng, Adsorption and corrosion inhibition performance of multiphytoconstituents from Dioscorea septemloba on carbon steel in acidic media: Characterization, experimental and theoretical studies, Colloids Surfaces A Physicochem. Eng. Asp., 2020, 590, 1-13. doi: 10.1016/j.colsurfa.2020.124534

40. A.S. Fouda, M. Eissa and A. El-Hossiany, Ciprofloxacin as Eco-Friendly Corrosion Inhibitor for Carbon Steel in Hydrochloric Acid Solution, Int. J. Electrochem. Sci., 2018, 13, 11096-11112. doi: 10.20964/2018.11.86

41. Y. Li and Y.F. Cheng, Effect of surface finishing on early-stage corrosion of a carbon steel studied by electrochemical and atomic force microscope characterizations, Appl. Surf. Sci., 2016, 366, 95-103. doi: 10.1016/j.apsusc.2016.01.081

42. Y. Baymou, H. Bidi, M. Ebn Touhami, M. Allam, M. Rkayae and R.A. Belakhmima, Corrosion Protection for Cast Iron in Sulfamic Acid Solutions and Studies of the Cooperative Effect Between Cationic Surfactant and Acid Counterions, J. Bio- and Tribo-Corrosion, 2018, 4. doi: 10.1007/s40735-018-0127-2

43. E.K. Ardakani, E. Kowsari and A. Ehsani, Imidazolium derived polymeric ionic liquid as a green inhibitor for corrosion inhibition of mild steel in $1.0 \mathrm{M} \mathrm{HCl}$ : Experimental and computational study, Colloids Surfaces A Physicochem. Eng. Asp., 2020, 586, 124195. doi: 10.1016/j.colsurfa.2019.124195

44. G. Gece and S. Bilgiç, Quantum chemical study of some cyclic nitrogen compounds as corrosion inhibitors of steel in $\mathrm{NaCl}$ media, Corros. Sci., 2009, 51, 1876-1878. doi: 10.1016/j.corsci.2009.04.003

45. J.M. Roque, T. Pandiyan, J. Cruz and E. García-Ochoa, DFT and electrochemical studies of tris(benzimidazole-2-ylmethyl)amine as an efficient corrosion inhibitor for carbon steel surface, Corros. Sci., 2008, 50, 614-624. doi: 10.1016/j.corsci.2007.11.012

46. M.A. Hegazy, Novel cationic surfactant based on triazole as a corrosion inhibitor for carbon steel in phosphoric acid produced by dihydrate wet process, J. Mol. Liq., 2015, 208, 227-236. doi: 10.1016/j.molliq.2015.04.042 